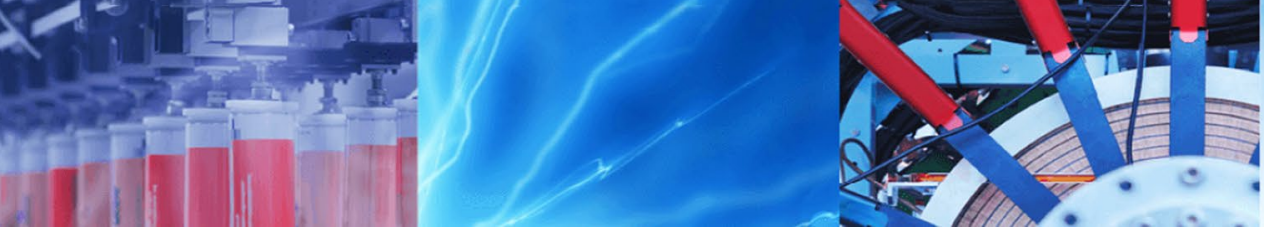

Research Article

\title{
Synthesis of attapulgite/graphene conductive composite and its application on waterborne coatings
}

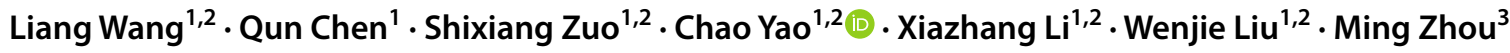

(c) Springer Nature Switzerland AG 2019

\begin{abstract}
Attapulgite/graphene conductive composite is modified by a silane coupling agent of $N$-( $\beta$-aminoethyl)- $\gamma$ aminopropyltrimethoxy-silane ( $\mathrm{KH}-792)$ to make conductive attapulgite uniformly load on the surface of the graphene. The samples are characterized by X-ray diffraction, transmission electron microscopy and Fourier transform infrared spectroscopy. The results demonstrate that the conductive attapulgite is successfully grafted onto the surface of graphene. The characteristics of raw and modified absorbents are characterized by Fourier transform infrared spectroscopy, thermal analysis, scanning electron microscopy and transmission electron microscopy. The results show that the saturated mass fraction of the surface-adsorbed $\mathrm{KH}-792$ silane coupling agent is about 3.0-5.0\%. The electrical conductivity and mechanical properties of the conductive coating prepared from the modified conductive composite are investigated. The results show that the surface resistivity of the modified attapulgite/graphene conductive composite coating is smaller than that of the unmodified attapulgite/graphene conductive composite coating when the same amount of is added, and the mechanical properties are also greater than unmodified. As a comparison, when the composite material is $15 \%$ mass of the paint which can achieve a best performance.
\end{abstract}

Keywords Graphene - Conductive attapulgite · Silane coupling agent - Surface modification P Polyurethane waterborne coating

\section{Introduction}

Conductive coating is a special functional widely used for coating on the surface of non-conductive substrates, which has a certain of conduction current, eliminates static charge and corrosion resistance [1]. The composition of conductive coatings contains resin, pigment, fillers, curing agents, solvents and additives [2]. Volatile organic substance (VOC) is commonly used as solvents for traditional conductive coatings which will cause pollution in the operation room volatilizing during the film formation process and cause secondary pollution to the atmospheric environment. If humans and animals are exposed in high concentrations of VOC for a long time, it will increase the likelihood of concurrent cancer [3]. Therefore, the traditional coatings industry needs to be upgraded and transformed. Now, water-based coatings have low VOC and even zero VOC emissions [4], which can improve production environment, reduce the cost of solvents. It reduces the production cost and makes the waterborne coatings more competitive. Therefore, it is inevitable that the waterborne coatings will gradually replace the solvent-based coatings $[4,5]$.

The ratio of filler to resin in conductive coatings is the decisive factor for its performance. Conductive fillers mainly include carbon system [6], metal system [7], metal oxide system [8] and so on. Tin oxide $\left(\mathrm{SnO}_{2}\right)$ is an n-type semiconductor with a wide bandgap, excellent

Chao Yao, yaochao420@163.com | 'School of Petrochemical Engineering, Changzhou University, Changzhou 213164, People's Republic of China. ${ }^{2}$ R\&D Center of Xuyi Attapulgite Applied Technology, Changzhou University, Xuyi 211700, People's Republic of China. ${ }^{3}$ Changzhou Wujin Chenguang Metal Coating Co., Ltd., Changzhou 213118, People's Republic of China.

SN Applied Sciences (2019) 1:288 | https://doi.org/10.1007/s42452-019-0311-0 
mechanical properties, high visible light transparency and high stability. It has better conductivity after doping $\mathrm{Sb}$ in $\mathrm{SnO}_{2}$ lattice [9]. Attapulgite clay, referred to as attapulgite, also known as palygorskite, is a onedimensional nanostructured magnesium-rich silicate clay mineral natural crystalline material with rod-like or fibrous micro-morphology [10]. Graphene has excellent electrical conductivity, but it is prone to wrinkles and self-agglomeration. It reduces its excellent electrical conductivity in the coating system. Therefore, attapulgite is introduced to support the graphene sheet layer in the coating system, thereby reducing wrinkles and agglomeration of graphene. At the same time, because graphene is expensive, in order to reduce the production cost and reduce the amount of graphene, the surface of the attapulgite is coated with antimony doped tin oxide (ATO) to make it have conductive properties, and the conductive attapulgite, attapulgite is obtained. The stone itself does not have electrical conductivity. The antimony-doped tin oxide (ATO) is uniformly coated on the surface of the attapulgite, so that the attapulgite has electrical conductivity and reduces the amount of graphene. The conductive attapulgite and graphene are introduced into the waterborne coating system to achieve better application effects. The crystal has a diameter of 20-40 nm and a length of 500-5000 nm [11]. The basic structural unit consists of a siloxane tetrahedral double chain parallel to the c-axis. Each chain is connected by an oxygen atom to form nanorod structure with a special high aspect ratio [12]. The precursor is prepared by coating the ATO particles on the attapulgite by a coprecipitation method. The conductive attapulgite composite material is obtained by calcination. Graphene is a two-dimensional (2D) honeycomb lattice material formed by the close combination of planar single-layer carbon atoms [13]. It is only $0.3354 \mathrm{~nm}$ thick and is the world's thinnest two-dimensional material [14]. Graphene has a very high theoretical specific surface area $\left(2630 \mathrm{~m}^{2} / \mathrm{g}\right)$ [15], which can be used to load various molecules including metals, metal oxides, biomolecules, fluorescent molecules and various drugs [16]. In addition, graphene has excellent mechanical properties (tensile strength up to $130 \mathrm{GPa}$ is the highest of all known materials [17]), electrical conductivity and corrosion resistance. In order to make better use of the excellent properties of graphene, Meyer et al. [18] used it as a typical two-dimensional reinforcement phase, preparing the materials with different functions of graphene as the modified phase. And the conductive attapulgite/ graphene is modified by surfactant to load on the surface of graphene sheet to form a three-dimensional network cross-linked structure, which reduces the folding agglomeration of graphene sheets to achieve better conductivity and corrosion resistance.

\section{Experiment}

\subsection{Experimental materials and chemicals}

Conductive attapulgite: Changzhou Naou Technology Co., Ltd.; Graphene: laboratory-made; polyurethane resin: industrial grade, Kunshan Kelijia International Trade Co., Ltd.; defoamer BYK-110: analytical grade, BYK; silane coupling $N$-( $\beta$-aminoethyl)- $\gamma$-aminopropyltrimethoxys ilane(KH-792): analytical grade, Aladdin; leveling agent EFKA3600N: analytical grade, BYK; cellulose, curing agent, ethanol, leveling agent: Analytical pure, Sinopharm Chemical Reagent Co., Ltd.

\subsection{Conductive attapulgite/graphene surface treatmentIn}

Before the experiment, we took $40 \mathrm{~g}$ of conductive attapulgite/graphene powder with an electronic balance, added $400 \mathrm{~g}$ of ethanol at a mass ratio of 1:10, mixed them and dispersed them in a beaker which was transferred to a four-necked flask. The four-necked flask was heated in a water bath at $70^{\circ} \mathrm{C}$. When the internal temperature of the four-necked flask was about $65^{\circ} \mathrm{C}$, the $\mathrm{PH}$ was adjusted to 3-4 with $0.1 \mathrm{~mol} / \mathrm{L} \mathrm{HCl}$ solution. $\mathrm{KH}-792[\mathrm{~m}(\mathrm{KH}-792): \mathrm{m}$ $($ Composite material $)=0.01,0.02,0.03,0.05,0.06]$ was added to the four-necked flask. The reaction mixture was stirred at $70^{\circ} \mathrm{C}$ for $3 \mathrm{~h}$. The product was washed with deionized water until the filtrate was without $\mathrm{Cl}^{-}$, subsequent to which the product was dried under vacuum at $80^{\circ} \mathrm{C}$ for $12 \mathrm{~h}$. The powder was sieved to obtain a modified conductive attapulgite/graphene.

\subsection{Composite mechanism}

The attapulgite is coated with a layer of ATO conductive film to prepare the conductive attapulgite [19]. However, the surface hydroxyl groups of the conductive attapulgite are reduced after coating, which not only make it weaker in binding to graphene sheetsbut also affect the dispersion in the polyurethane aqueous coating. Therefore, the graphene/conductive attapulgite was modified by the surfactant $N$-( $\beta$-aminoethyl)- $\gamma$-aminopropyltrimethoxysilane to get favorable dispersibility and cross-linking with graphene sheets forming a three-dimensional network crosslinked structure [20]. It prevents the folding agglomeration of the graphene sheetsto obtain the better property of conductivity and corrosion resistance in Fig. 1. 
Fig. 1 The mechanism of graphene/conductive attapulgite composite

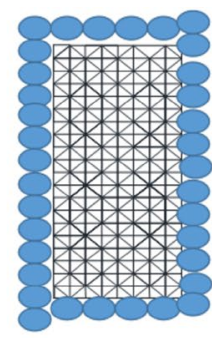

graphene

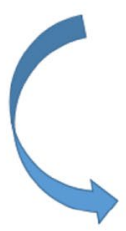

$-\mathrm{OH}$

Table 1 The formulation of coating

\begin{tabular}{ll}
\hline Raw material & $\mathrm{m} / \mathrm{g}$ \\
\hline Polyurethane resin & 20 \\
Deionized water & 50 \\
graphene & 1 \\
Conductive attapulgite or conductive attapulgite/graphene & $10-30$ \\
Defoamer & 0.8 \\
Cellulose & 1 \\
Leveling agent & 1.2 \\
Hardener & 2
\end{tabular}

\subsection{Complex treatment process}

The polyurethane resin was weighed $60 \mathrm{~g}$ with an electronic balance, followed by the addition of $100 \mathrm{~g}$ of deionized water. The solution was put in the homogenizer and dispersed at high speed of $1500 \mathrm{r} / \mathrm{min}$ for $5 \mathrm{~min}$. The graphene/conductive attapulgite powder and a small amount of antifoaming agent, leveling agent and curing agent are dispersed in the solution for $30 \mathrm{~min}$ to prepare the conductive paint. The formulation of coating is shown in Table 1.

\section{Results and discussion}

\subsection{XRD analysis of composites materials}

Figure 2 shows the X-ray diffraction spectrum of graphene (a), conductive attapulgite/graphene (b) and conductive attapulgite (c). Comparing the three graphs (a), (b), and (c), we found that (b) the characteristic peaks of the
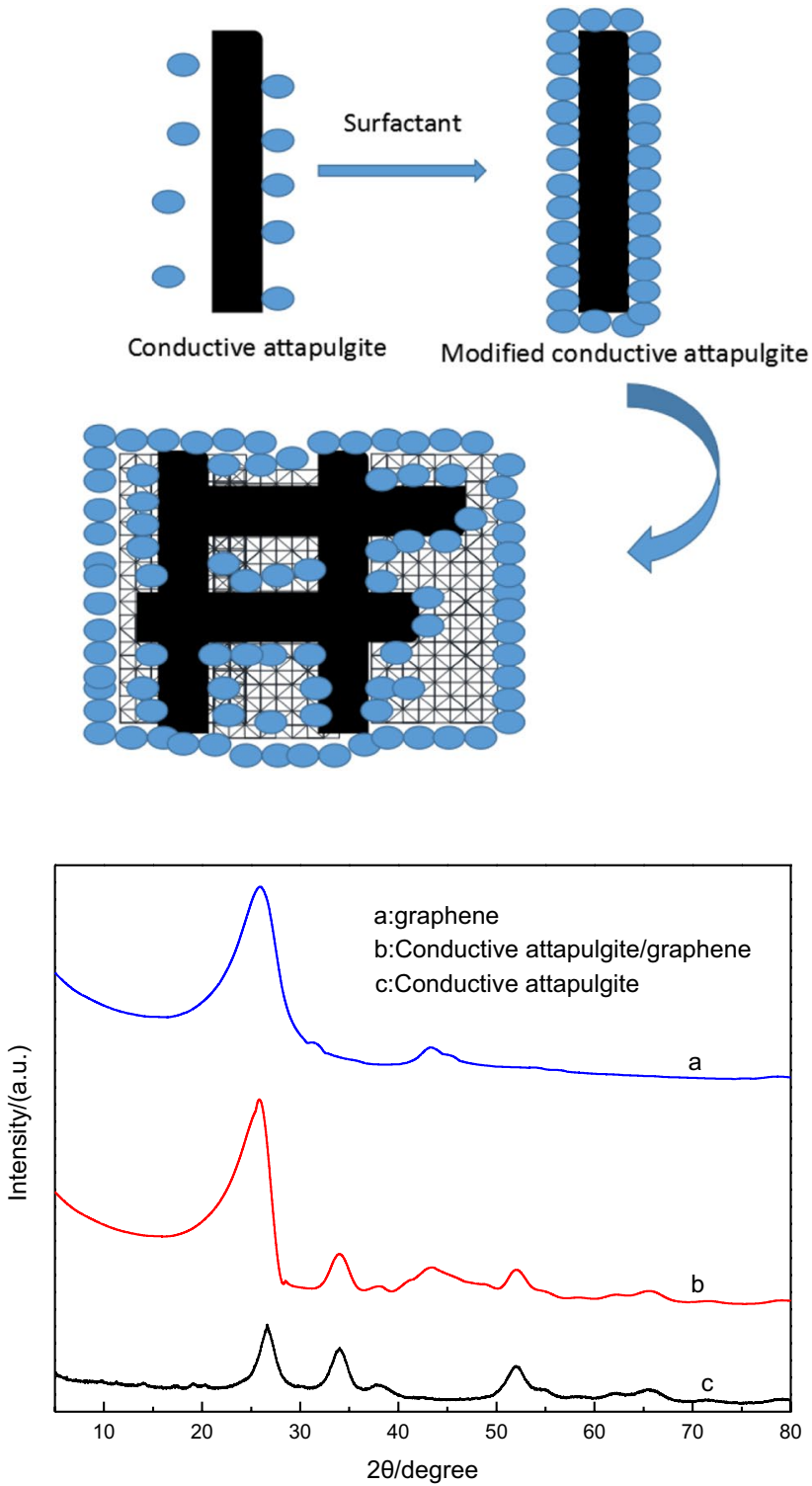

Fig. 2 XRD pattern of graphene (a), conductive attapulgite/graphene (b) and conductive attapulgite (c)

conductive attapulgite appear in the conductive attapulgite/graphene, and the characteristic peak of graphene also appears. It can be indirectly proved that the conductive attapulgite has stitching on the surface of graphene, the Fourier infrared and projection electron microscopy will further prove this composite mode.

\subsection{Infrared spectrum analysis of composites materials}

The infrared spectrum of the conductive attapulgite/graphene and the modified conductive attapulgite/graphene is shown in Fig. 3. The unmodified conductive attapulgite/graphene showed a $\mathrm{Si}-\mathrm{O}-\mathrm{H}$ anti-symmetric stretching 


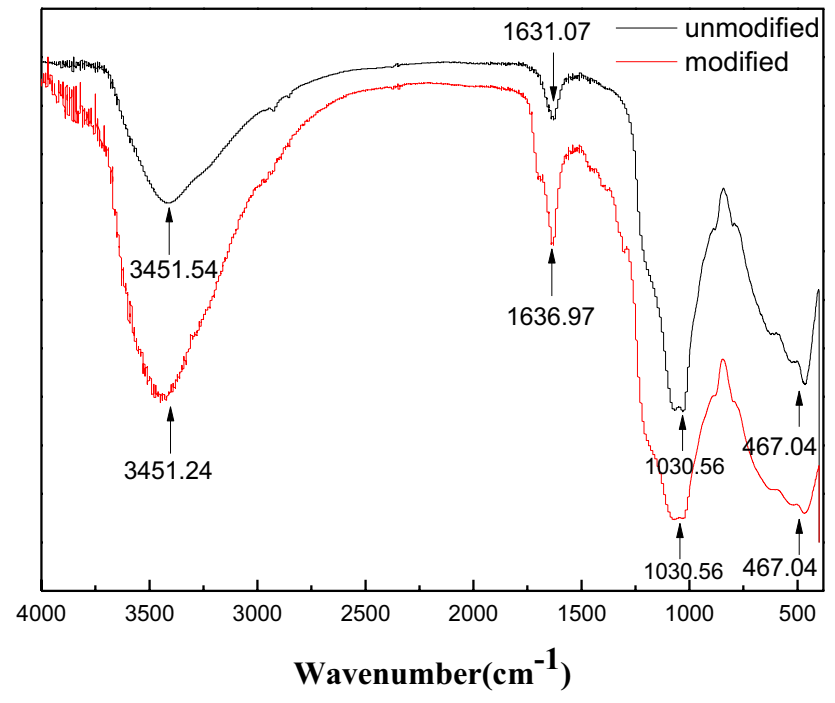

Fig. 3 FT-IR spectra of composite materials

peak bound to water at $3451 \mathrm{~cm}^{-1}$ and the bending vibration absorption peak of $\mathrm{H}-\mathrm{O}-\mathrm{H}$ appeared at $1631 \mathrm{~cm}^{-1}$ and $1030 \mathrm{~cm}^{-1}$ [21]. There is an absorption peak of C-O-C, which may be formed by the surface group of the conductive attapulgite and the surface group of graphene. After modification with a $\mathrm{KH}-792$ silane coupling agent, the absorption peak intensity is also enhanced, indicating that the conductive attapulgite/graphene compound is more thorough, this also indicates the modification effect is good.

\subsection{Thermal analysis of composites materials}

Figure 4 shows the thermogravimetric analysis of unmodified conductive attapulgite/graphene and modified conductive attapulgite/graphene with different amounts of $\mathrm{KH}-792$. When the temperature is below $200^{\circ} \mathrm{C}$, the weight loss rate of the conductive attapulgite/graphene is about $2.13 \%$, which is caused by the removal of crystal water. When the temperature is between 200 and $600{ }^{\circ} \mathrm{C}$, the weight loss rate of the conductive attapulgite/graphene is $3.74 \%$ because the crystal water on the surface of the material is completely removed caused the removal of structural water. After modification with $\mathrm{KH}-792$ silane coupling agent, the weight loss rate will reach $6.28 \%$ and $6.60 \%$ when the coating ratio is $1 \%$ and $3 \%$, respectively. It may be due to the burning of organic group on the surface of the modified conductive attapulgite/graphene. In the figure, the trend of the thermogravimetric curve is basically consistent when the amount of modifier is $5 \%$ and $3 \%$, indicating that the surface of the composite has reached saturated adsorption. Thus, the optimum dosage

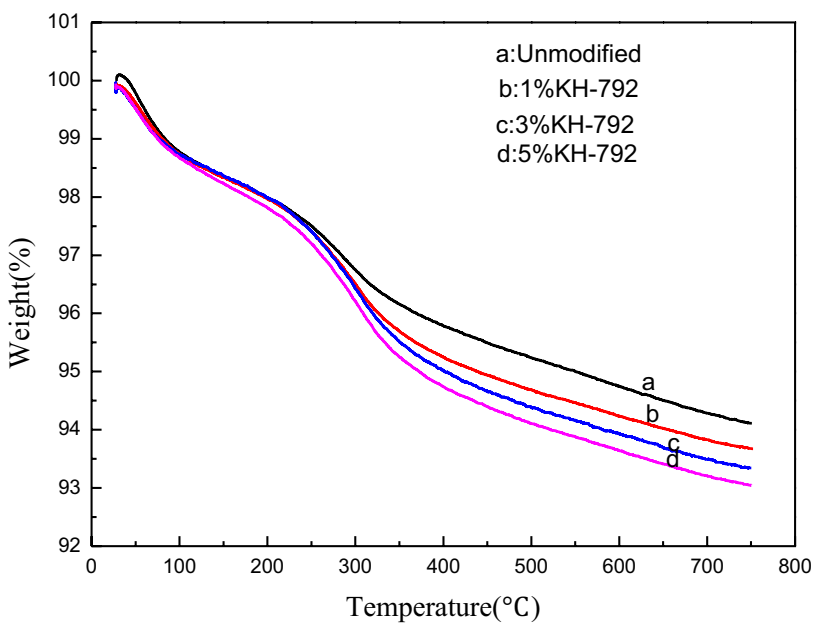

Fig. 4 TG curve of composites before and after modification a Composite material; b $\mathrm{m}(\mathrm{KH}-792): \mathrm{m}($ Composite material $=0.01 ; c \mathrm{~m}(\mathrm{KH}-792): \mathrm{m}($ Composite material $)=0.03 ; \mathrm{d} \mathrm{m}(\mathrm{KH}-$ 792): $\mathrm{m}($ Composite material $)=0.05$

of the modifier is $3-5 \%$. The data shown in Table 2 is that of the mass change of samples in different temperature.

\subsection{TEM and SEM analysis of composites materials}

The TEM images of the conductive attapulgite and composite are shown in Fig. 5. It can be seen in Fig. 5a that the $\mathrm{Sb}-\mathrm{SnO}_{2}$ particles form a continuous and dense conductive layer on the surface of the attapulgite with a thickness about $20 \mathrm{~nm}$. A very pronounced sheet structure of graphene can be seen in Fig. 5b. In Fig. 5c, which can been see that a small amount of conductive attapulgite is presented on the graphene surface. It may be because the graphene sheet layer is curled and moreconductive attapulgites are formed freely on the outside, which cannot form three-dimensional crosslinks with the graphene structure. Figure $5 \mathrm{~d}$ shows the modified conductive attapulgite/graphene. We can clearly see that the conductive attapulgite appears on the surface of the graphene sheet to reduce the wrinkles of graphene.

Table 2 The mass change of samples in different temperature

\begin{tabular}{lll}
\hline Sample & $0-200{ }^{\circ} \mathrm{C}$ weight loss/\% & $\begin{array}{l}200-600{ }^{\circ} \mathrm{C} \\
\text { weight loss } / \%\end{array}$ \\
\hline Unmodified & 2.13 & 3.74 \\
$1 \% \mathrm{KH}-792$ & 2.15 & 4.13 \\
$3 \% \mathrm{KH}-792$ & 2.15 & 4.47 \\
$5 \% \mathrm{KH}-792$ & 2.18 & 4.52 \\
\hline
\end{tabular}




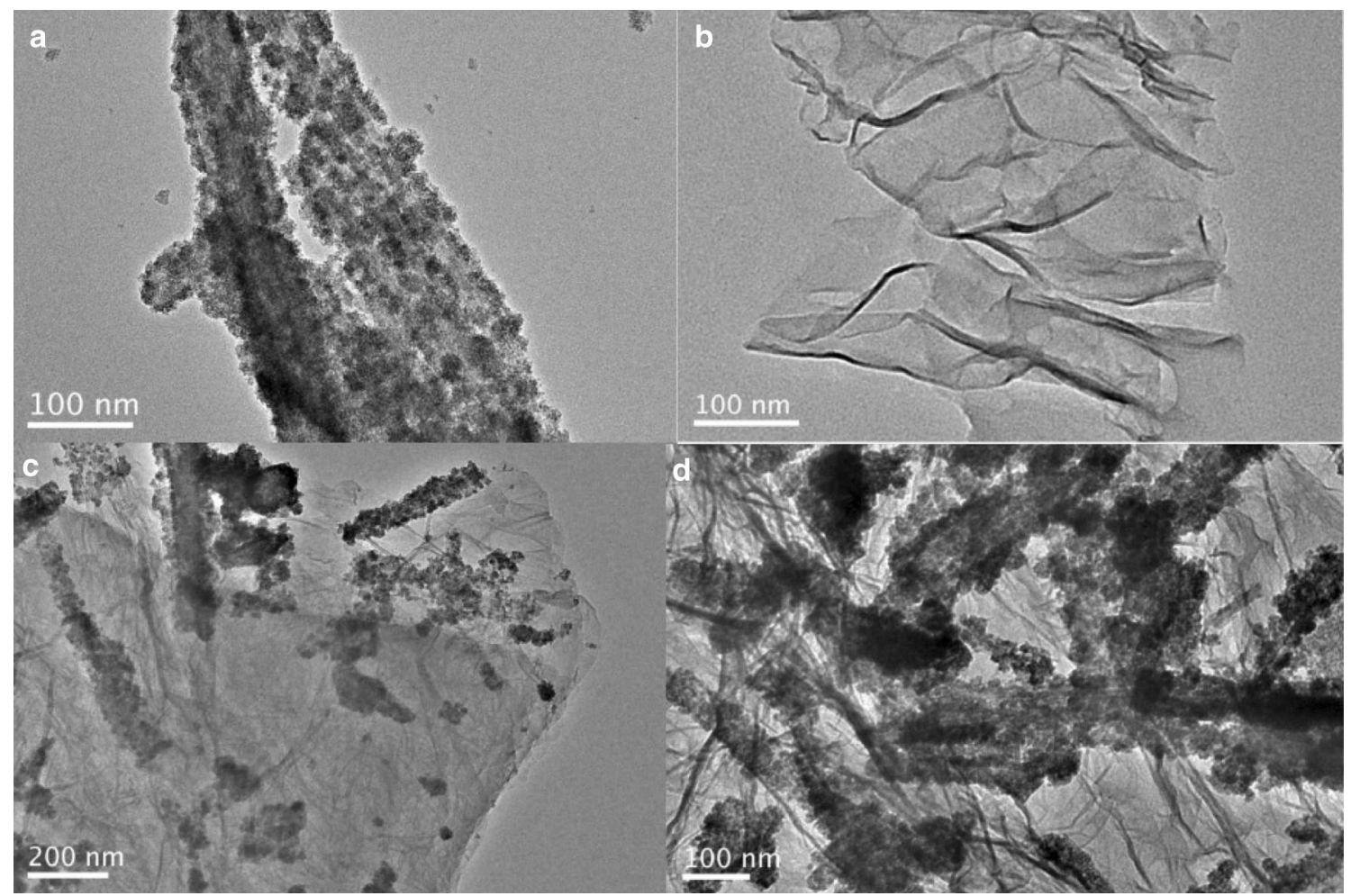

Fig. 5 TEM images of a conductive attapulgite, $\mathbf{b}$ graphene, $\mathbf{c}$ conductive attapulgite/graphene, $\mathbf{d}$ modified conductive attapulgite

The SEM image of the conductive attapulgite and the composite material are shown in Fig. 6. From Fig. 6a, it shows that the unmodified conductive attapulgite/graphene are not well combined and there are many conductive attapulgites in a free state. If it is used as a coating meterial, it will reduce the mechanical properties of the coating. However, it can been observed that the conductive attapulgite and graphene are cross-linked after modification by the silane coupling agent in Fig. 6b. The conductive attapulgite is arranged on the graphene sheet to prevent the graphene sheet from wrinkling conductive properties of the conductive attapulgite can reduce the agglomeration of graphene sheets to achieve better performance.

Figure 7 is the SEM image of the addition of conductive attapulgite/graphene and modified conductive attapulgite/graphene coating. As shown in Fig. 7(a), (b), obvious cocoon-like agglomeration and large voids appear in the coating when conductive attapulgite/graphene is added, which failed to form a complete conductive network,

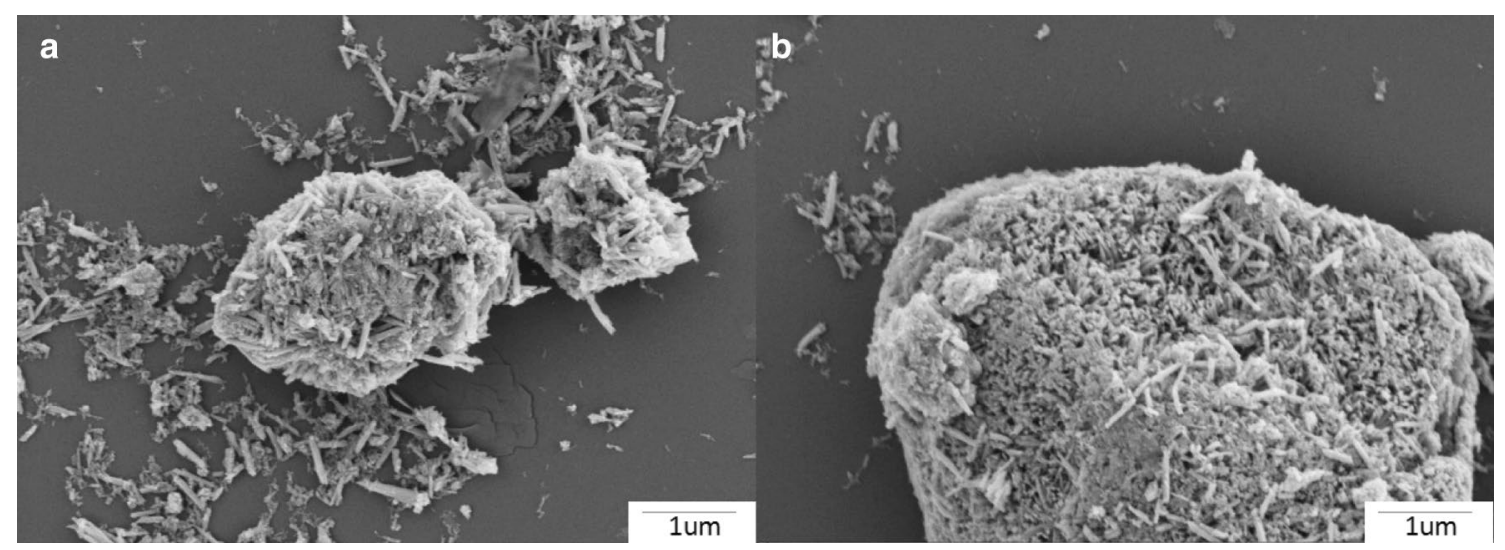

Fig. 6 SEM image of a conductive attapulgite/graphene, $\mathbf{b}$ modified conductive attapulgite/graphene 


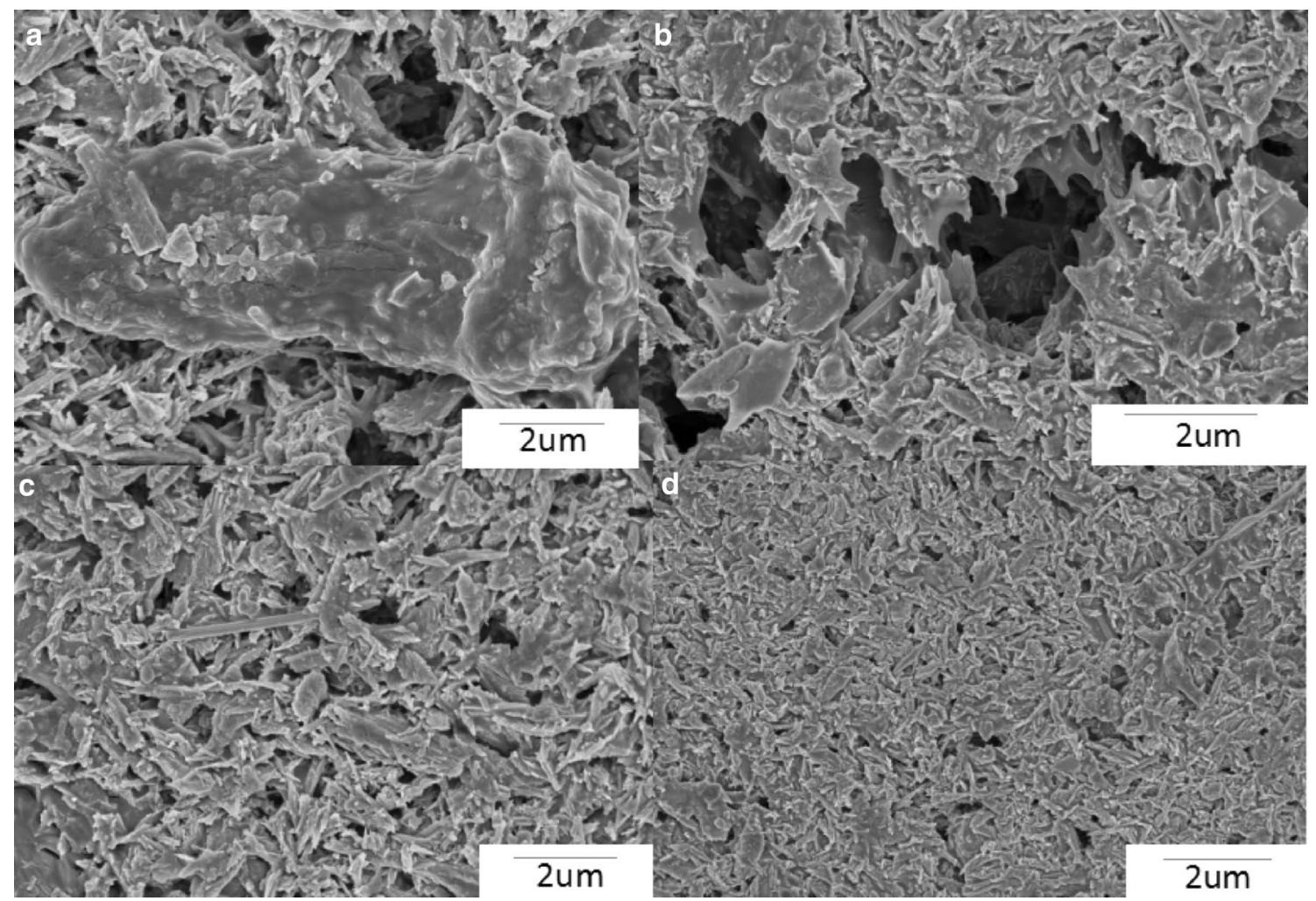

Fig. 7 SEM images of $\mathbf{a}$, $\mathbf{b}$ electro-attapulgite/graphene coating; $\mathbf{c}, \mathbf{d}$ modified conductive attapulgite/graphene coating

indicating that the graphene was unevenly dispersed in the coating resulting in the appearance of the coating. because of that the coating fails to form a complete conductive network, indicating graphene is unevenly dispersed in the coating and agglomerated in the coating, causing voids in the coating and affecting its electrical conductivity and affecting its electrical conductivity. From Fig. 7(c), (d), the modified conductive attapulgite/ graphene coating are uniformly dispersed in the resin without agglomeration. The middle fillers are bridged with each other to form a complete conductive path making the prepared coating with an excellent electrical conductivity, which is consistent with the results of surface resistance value.

\subsection{Surface resistance and AC impedance curve and salt spray test analysis}

The amount of conductive filler added is measured as a percentage of the total coating system. The surface resistance of the composite coating is shown in Fig. 8. As shown in the figure, the surface resistance of the coating decreases with the increase of the conductive filler increases and Surface resistance refers to the coating formed after the coating is applied to a non-conductive plastic sheet, and the resistance of the surface of the

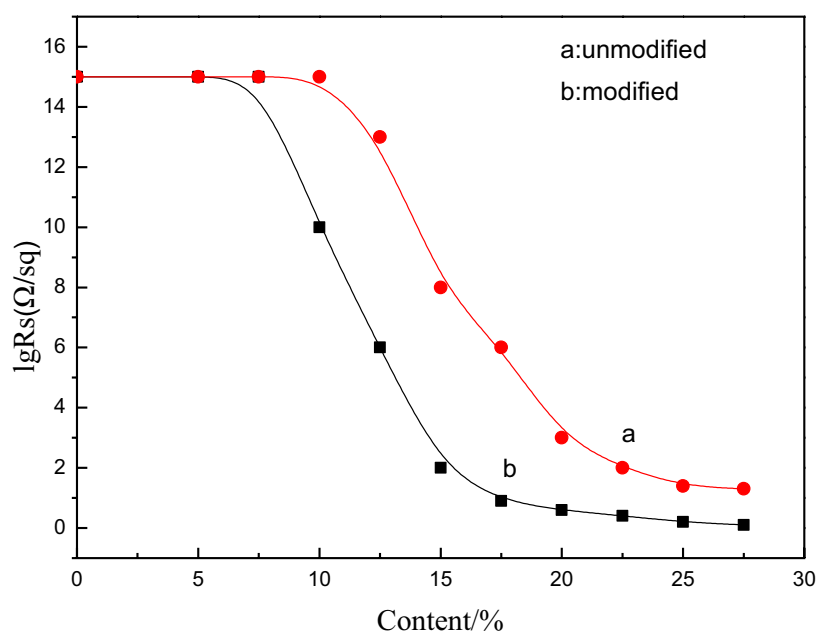

Fig. 8 Effect of modifier on surface resistance of coating

coating is measured by four probes. According to seepage threshold theory, as the content of conductive filler increases, the probability of formation of conductive network becomes larger and larger and the gap between particles becomes smaller and smaller. When the content of conductive filler reaches a critical value, the particles originally dispersed in the coating system will contact each other to form a complete conductive path, which 
is macroscopically manifested in a rapid decrease in the resistance of the composite coating. When the conductive network is completely formed, the resistance will tend to be stable and the addition of conductive filler will have little effect on the resistance [22, 23]. In addition, the surface resistance of the modified conductive coating is significantly smaller than that the unmodified coating at the same conductive filler content because the modified conductive filler has better dispersibility in an aqueous solvent at low contents. Meanwhile, a complete conductive path has also been formed.

Figure 9 is the AC impedance curve of conductive attapulgite, graphene, conductive attapulgite/graphene and modified conductive attapulgite/graphene in the coating. We can get the components in the coating from the slope of the curve in the figure. The covers show that the coatings have conductivity and corrosion resistance. We

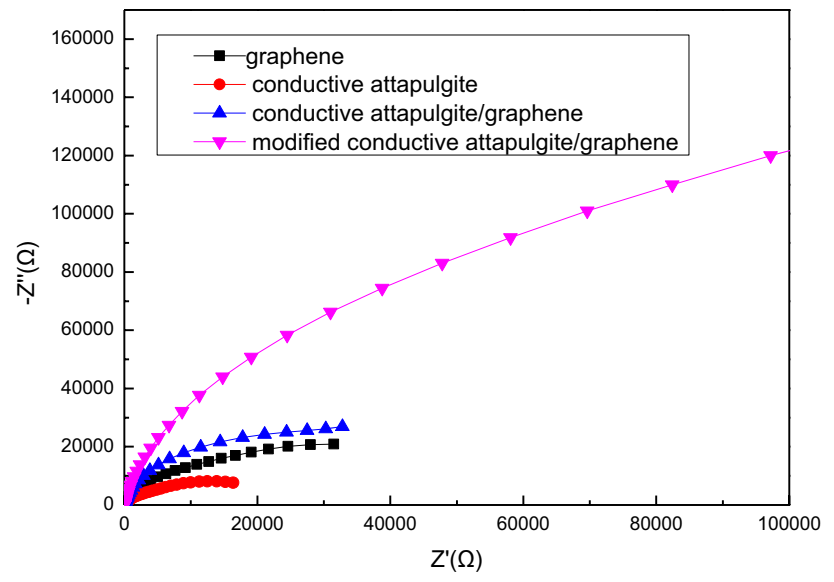

Fig. 9 AC impedance curves of different material coatings can then find that the performance of modified conductive attapulgite/graphene > conductive attapulgite/graphene $>$ conductive attapulgite. Therefore, the accuracy of the surface resistance curve value of the coating can be proved. It is also shown that the modifier does contribute to the recombination of the conductive attapulgite/ graphene.

Figure 10 is a photograph of a carbon steel sample coated with a conductive attapulgite coating and a modified conductive attapulgite/graphene coating after a $120 \mathrm{~h}$ salt spray test. Figure $10(\mathrm{a})$ is a conductive attapulgite coating and Fig. 10(c) is the modified conductive attapulgite/graphene coating before the salt spray test. After the salt spray test, it is found that the conductive attapulgite is unevenly dispersed in the aqueous polyurethane paint, we can see there is a large area of corrosion occurring in carbon steel sheet. However, in the comparison of (b) and (d), the carbon steel sheet with the modified conductive attapulgite/graphene coating (d) is substantially free of corrosion, and on the carbon steel sheet, we find the corrosion occurring on the surface of the carbon steel where no coating was applied., this also indicates that the addition of graphene played a role in slowing down corrosion.

After the salt spray test, we also make a comparison of the quality changes of the samples. The quality change of the sample can also reflect the degree of corrosion in another aspect. The data shown in Table 3 is that of the mass change of the pre-coated and post-coated carbon steel samples. It can be seen from the data that the modified conductive attapulgite/graphene coating has the least mass loss, and the carbon steel surface has the least degree of corrosion, which confirms the salt spray test results to be right.
Fig. 10 Picture of the coating sample before and after the $120 \mathrm{~h}$ salt spray test

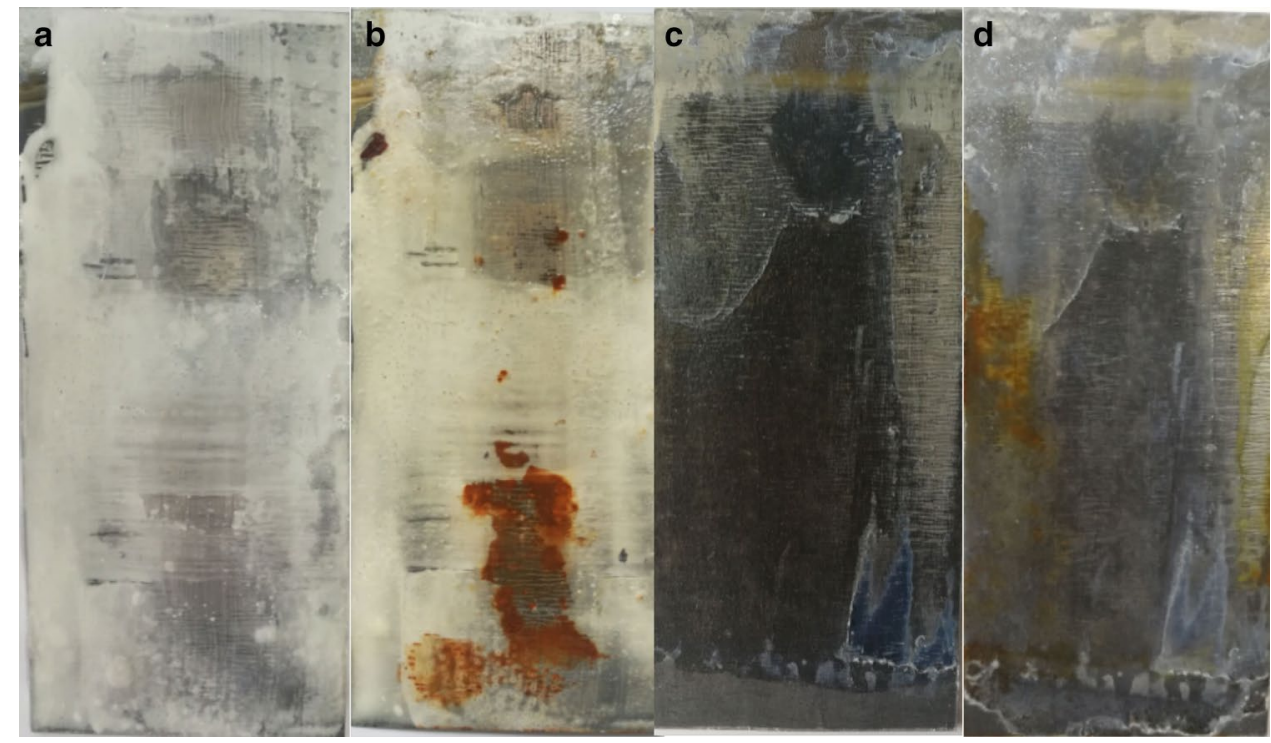

SN Applied Sciences a SPRINGER NatURE journa 
Table 3 Mass change and surface change of coated carbon steel after salt spray test

\begin{tabular}{|c|c|c|c|c|}
\hline Sample & $\begin{array}{l}\text { Pre-test } \\
\text { quality } \\
(\mathrm{m} / \mathrm{g})\end{array}$ & $\begin{array}{l}\text { Post-experi- } \\
\text { ment quality } \\
(\mathrm{m} / \mathrm{g})\end{array}$ & Quality loss (m/g) & Surface condition \\
\hline Carbon steel & 15.3325 & 15.2038 & 0.1287 & A lot of rust \\
\hline Conductive attapulgite coating & 16.5387 & 16.3628 & 0.1759 & Partially rusty \\
\hline $\begin{array}{l}\text { Modified conductive attapulg- } \\
\text { ite/graphene coating }\end{array}$ & 16.5517 & 16.4928 & 0.0589 & Basically not rusting \\
\hline
\end{tabular}

Table 4 Effect of different filler loadings on other properties of conductive attapulgite/graphene coating

\begin{tabular}{lllll}
\hline Add amount & Hardness & Adhesion & $\begin{array}{l}\text { Flexibility } \\
(\mathrm{mm})\end{array}$ & $\begin{array}{l}\text { Impact } \\
\text { resistance } \\
(\mathrm{cm})\end{array}$ \\
\hline 5 (wt\%) & 5B & 2 & 1 & 35 \\
7.5 (wt\%) & 5B & 2 & 1 & 35 \\
10 (wt\%) & 4B & 2 & 1 & 40 \\
12.5 (wt\%) & 3B & 1 & 1 & 45 \\
15 (wt\%) & 3B & 1 & 1 & 45 \\
17.5 (wt\%) & 3B & 2 & 1 & 45 \\
\hline
\end{tabular}

Table 5 Effect of different filler contents after modification on other properties of conductive attapulgite/graphene coating

\begin{tabular}{lllll}
\hline Add amount & Hardness & Adhesion & $\begin{array}{l}\text { Flexibility } \\
(\mathrm{mm})\end{array}$ & $\begin{array}{l}\text { Impact } \\
\text { resistance } \\
(\mathrm{cm})\end{array}$ \\
\hline 5 (wt\%) & $3 B$ & 2 & 1 & 40 \\
$7.5(w t \%)$ & $3 B$ & 1 & 1 & 40 \\
$10(w t \%)$ & $3 B$ & 1 & 1 & 45 \\
12.5 (wt\%) & 2B & 1 & 1 & 45 \\
15 (wt\%) & B & 1 & 1 & 50 \\
17.5 (wt\%) & B & 2 & 1 & 45 \\
\hline
\end{tabular}

\subsection{Other performance characterization of the coating}

The mechanical properties of the composite conductive attapulgite/graphene coating and the modified composite conductive attapulgite/graphene coating are shown in Tables 4 and 5. It can be seen that as the filler content increases, the hardness and impact resistance of the modified composite conductive attapulgite/graphene coating increase: the hardness increases from $3 B$ to $B$, and the impact resistance increases from 45 to $50 \mathrm{~cm}$. At the same time, the flexibility of the coating remains unchanged. When the modified composite conductive attapulgite/graphene coating is added in an amount of more than $15 \%$, the filler cannot be completely wrapped by the resin to form a gap, and too much filler makes the coating too viscous. Which cause the mechanical properties performance of the coating correspondingly degradation.

\section{Conclusion}

In this paper, the composite conductive attapulgite/graphene material was modified by $\mathrm{KH}-792$ silane coupling agent, we can verify the silane coupling agent was successfully grafted into the conductive attapulgite composite by XRD, TEM and FT-IR. The surface of the powder is applied to the modified conductive composite. The results show that the $\mathrm{KH}-792$ silane coupling agent helps the conductive attapulgite/graphene surface to bond by chemical bonds, and they are cross-linked to form a threedimensional network structure. The modifier changes the properties of the conductive attapulgite/graphene surface so that they are evenly combined. The results show that the modified conductive attapulgite/graphene composite powder has better dispersibility and anti-corrosion performance in polyurethane water-based pain, the surface resistance of the modified powder is also better than the unmodified conductive attapulgite/graphene when the same amount is added. We can measure the lowest surface resistance is $1.0 \times 10^{4} \Omega / \mathrm{sq}$. It also shows better adhesion, flexibility and impact resistance. The modified conductive composite powder achieves the best performance when the amount is $15 \%$, the hardness is $B$, the adhesion is 1 , the flexibility is $1 \mathrm{~mm}$, and the impact resistance is $50 \mathrm{~cm}$.

Acknowledgements This research by Innovative Team of Jiangsu Province(XCL-CXTD-029) and Key R\&D Programs of Jiangsu Province (BE2017064) provide financial support. The support of these two funds has enabled my research to proceed smoothly, and I am very grateful for their help.

\section{Compliance with ethical standards}

Conflict of interest They have no conflict of interest.

\section{References}

1. Du XS, Jiao HY (2009) Research progress of conductive coatings. China Coat 24(2):19-22

2. Swarup S, Simpson DA, Luchansky MS et al (2018) Curable filmforming compositions containing acid functional curing agents and multilayer composite coatings: U.S. Patent Application 15/296,548. 2018-4-19 
3. Liu GJ (2010) New technology of modern coating technology. China Light Industry Press, Beijing, pp 72-75

4. Ho J, Mudraboyina B, Spence-Elder C et al (2018) Water-borne coatings that share the mechanism of action of oil-based coatings. Green Chem 20(8):1899-1905

5. Haase MF, Grigoriev DO, Möhwald H et al (2012) Development of nanoparticle stabilized polymer nanocontainers with high content of the encapsulated active agent and their application in water-borne anticorrosive coatings. Adv Mater 24(18):2429-2435

6. Athawale VD, Nimbalkar RV (2011) Waterborne coatings based on renewable oil resources: an overview. J Am Oil Chem Soc 88(2):159-185

7. Azim SS, Satheesh A, Ramu KK, Ramu S, Venkatachari G (2006) Studies on graphite based conductive paint coatings. Prog Org Coat 55(1):1-4

8. Wu S (2007) Preparation of ultra-fine copper powder and its lead-free conductive thick film. Mater Lett 61(16):3526-3530

9. Daoli Z, Zhibing D, Jianbing Z, Liangyan C et al (2006) Microstructure and electrical properties of antimony-doped tin oxide thin film deposited by sol-gel process. Mater Chem Phys 98(2/3):353-357

10. Shuo WU, Zhao Q, Miao D et al (2010) Synthesis and characterization of $\mathrm{Sb}$-doped $\mathrm{SnO}_{2}-\left(\mathrm{CeO}_{2}-\mathrm{TiO}_{2}\right)$ composite thin films deposited on glass substrates for antistatic electricity and UVshielding. J Rare Earths 28(s1):189-193

11. Zhu Z, Fan W, Liu Z et al (2018) Construction of an attapulgite intercalated mesoporous g-C3N4 with enhanced photocatalytic activity for antibiotic degradation. J Photochem Photobiol A 359:102-110

12. Wang $A Q$, Wang WB, Zheng YA et al (2014) Crystallization of attapulgite rods and their nano-functional composites. Science Press, Beijing

13. Molle A, Goldberger J, Houssa M et al (2017) Buckled twodimensional xene sheets. Nat Mater 16(2):163

14. Chen TH (2003) Nanoscale mineralogy and geochemistry of suspension attapulgite clay. Hefei University of Technology, Hefei
15. Novoselov KS, Ueim AK, Morozov SV et al (2004) Electric field effect in atomically thin carbon films. Science 306(5696):666-669

16. Liu J, Cui L, Losic D (2013) Graphene and graphene oxide as new nanocarriers for drug delivery applications. Acta Biomater 9(12):9243-9257

17. Zhang YB, Tang TT, Girit C et al (2009) Direct observation of a widely tunable bandgap in bilayer grapheme. Nature 469(7248):820-823

18. Meyer JC, Geim AK, Katsnelson Ml et al (2007) The structure of suspended graphene sheets. Nature 446(7131):60-63

19. Kim KS, Zhao Y, Jang $\mathrm{H}$ et al (2010) Large-scale pattern growth of graphene films for stretchable transparent electrodes. Natur 457(7230):706-710

20. Tkalya $E E$, Ghislandi $M$, de With $G$ et al (2012) The use of surfactants for dispersing carbon nanotubes and graphene to make conductive nanocomposites. Curr Opin Colloid Interface Sci 17(4):225-232

21. Hu P, Yang H (2010) Controlled coating of antimony-doped tin oxide nanoparticles on kaolinite particles. Appl Clay Sci 48(3):368-374

22. Bilotti E, Zhang H, Deng H, Zhang R, Fu Q, Peijs T (2013) Controlling the dynamic percolation of carbon nanotube based conductive polymer composites by addition of secondary nanofillers: the effect on electrical conductivity and tuneable sensing behaviour. Compos Sci Technol 74:85-90

23. Shang Q, Hao S, Wang W, Fu D, Ma T (2013) Preparation and characterization of antistatic coatings with modified $\mathrm{BaTiO}_{3}$ powders as conductive fillers. J Adhes Sci Technol 27(24):2642-2652

Publisher's Note Springer Nature remains neutral with regard to jurisdictional claims in published maps and institutional affiliations. 